\title{
Discursos visuais que o grafite revela na/da cultura contemporânea ${ }^{1}$
}

\author{
Discursos visuales que le graffiti revela en/de la cultura contemporánea \\ Visual discourses that graffiti reveals in/of contemporary culture
}

\author{
Maria Regiane S. L. Barrozo 2 \\ José Serafim Bertoloto ${ }^{3}$ \\ Muryllo Rhafael Lorensoni ${ }^{4}$ \\ Sílvia Mara Davies 5
}

\begin{abstract}
Resumo
Este texto objetiva levantar uma discussão acerca do caráter de significação de aspectos vinculados a visualidades na arte do grafite e subjetivações socioculturais. Especialmente nas duas primeiras décadas do atual século, constatar o grafite em diferentes cidades do mundo chama atenção pelo significado presente em sua ação que dialoga entre o popular e o erudito quando este ganha o espaço de galerias e salões de artes. Tal reconhecimento e diálogo antes negados ao grafite é contextualizado nessa oportunidade como referência de análise social e experiência cultural vividas pela contemporaneidade, utilizando para isso, paradigmas da imagem existentes no grafite e que caracterizam aspectos de uma realidade cultural. $\mathrm{O}$ que essa técnica pode revelar sobre a contemporaneidade e em que medida sua existência reterritorializada pode descrever um discurso sobre a sociedade e a cultura contemporâneas é o objetivo desse momento. A experiência estética que a apreciação do grafite proporciona é uma permissão para continuar em uma rotina diária sem paradas e tempo para fruições do belo e do gosto, porque ela acontece por onde se passa e se renova atualizando informações e comunicações de acordo com a experiência individual sensível de vida, para sua recepção instantânea.
\end{abstract}

Palavras-Chave: Contemporaneidade; Cultura; Experiência Estética; Grafite.

\section{Resumen}

Este texto pretende plantear una discusión sobre el carácter de la importancia de los aspectos vinculados a las visualidades en el arte del grafito y las subjetividades socioculturales. Especialmente en las primeras dos décadas

\footnotetext{
${ }^{1}$ Artigo apresentado durante o I Congresso Internacional Online de Estudos sobre Culturas - \#Culturas, realizado de forma online, em Outubro de 2019.

${ }^{2}$ Doutoranda em Estudos de Cultura Contemporânea; Universidade Federal de Mato Grosso - UFMT/PPGECCO; Cuiabá, Mato Grosso, Brasil; regianemusique@gmail.com

${ }^{3}$ Doutor em Comunicação e Semiótica pela Pontifícia Universidade Católica de São Paulo PUC-SP. Docente do Programa de Pós-Graduação em Ensino da Universidade de Cuiabá - (UNIC). Docente Colaborador do Programa de Pós-Graduação em Estudos de Cultura Contemporânea na Universidade Federal de Mato Grosso (UFMT). Lattes: http://lattes.cnpq.br/4937833975814371; serafim.bertoloto@ gmail.com

${ }^{4}$ Doutorando em Estudos de Cultura Contemporânea; Universidade Federal de Mato Grosso - UFMT/PPGECCO; Cuiabá, Mato Grosso, Brasil; mlorensoni@hotmail.com

${ }^{5}$ Doutoranda em Estudos de Cultura Contemporânea; Universidade Federal de Mato Grosso - UFMT/PPGECCO; Cuiabá, Mato Grosso, Brasil; silvia.davies@srs.ifmt.edu.br
} 
del presente siglo, el grafito y las diferentes ciudades del mundo llama la atención sobre el significado actual en su acción que dialoga entre lo popular y lo erudito cuando gana el espacio de las galerías de arte y salones. Este reconocimiento y diálogo previamente negado a los grafitos se contextualiza en esta oportunidad como referencia de análisis social y experiencia cultural vivida por la contemporaneidad, usando para esto paradigmas de la imagen que existen en el grafito y que caracterizan aspectos de una realidad cultural. Lo que esta técnica puede revelar sobre la contemporaneidad y hasta qué punto su existencia reterritoriaalizado puede describir un discurso sobre la sociedad y la cultura contemporáneas es el proposito de ese momento. La experiencia estética que proporciona la apreciación del grafito es un permiso para continuar en una rutina diaria sin paradas y tiempo para disfrutar de la bello y del gusto, porque sucede donde sea que vayamos y se renueva al actualizar la información y las comunicaciones de acuerdo con la experiencia sensible de la vida del individuo, para su recepción instantánea.

Palabras claves: Contemporaneidad; Cultura; Experiencia Estetica; Grafito.

\begin{abstract}
This text aims to raise a discussion about the character of meaning of aspects linked to graffiti art images and socio-cultural subjectivities. Especially in the first two decades of the current century, seeing or graffiti in different cities around the world draws attention for the meaning present in its action that dialogues between the popular and the learned when it gains space for galleries and art halls. Such recognition and dialogue before denying graffiti is contextualized in this opportunity, as a reference for social analysis and cultural experience lived by contemporaneity, using paradigms of the image existing in graffiti and the characterize aspects of a cultural reality. What this technique can reveal about contemporaneity and what its reterritorialized measure can describe a discourse on contemporary society and culture or the objective of that moment. The aesthetic experience that graffiti offers is a permission to continue a daily routine without interruptions and time to enjoy the beauty and taste, because it happens wherever it goes and currently the information and notifications are renewed according to a sensitive individual experience of life, for your instant reception.
\end{abstract}

Keywords: Contemporaneity; Culture; Aesthetic; Experience; Graphite.

\title{
1. Introdução
}

Não se refere à dimensão artística prática, se refere à dimensão artística na experiência estética das percepções que ocorrem nas relações sociais agenciadas naturalmente pelo contexto de vida recebido. O que é observado no grafite vai além do que se vê em um primeiro momento, não apenas pelo fato de alguns conteúdos remeterem a questões políticas, sociais, denúncias e realidades sensíveis às reflexões da realidade cotidiana. A colocação que aqui se infere ao grafite é de comportamento de todo um momento social. As características de operação dessa arte, seu modo de produção e circulação dialogam justamente com as necessidades e intensidades de movimentos, convívios, relações, informações e comunicações efêmeras, as mesmas sentidas e articuladas socialmente em tempos de tecnologias diluentes do tempo e do espaço.

O importante - para uma experiência estética que sugere a arte enquanto sintoma de análise cultural - não é o conteúdo do grafite, mas o que sua realização, sua existência nesse momento histórico com seu modo particular, revela sobre a cultura contemporânea e diagnostica aspectos de uma realidade social. O potencial em averiguar uma arte enquanto cultura está na significação que damos a ela. Relatos são episódios de uma estética 
padronizada que detinha rigores a serviço de poucos indivíduos com acesso monetário e “intelectual" para se submeterem a essa factível apreciação. A estética que abre espaço à experiência não sobrevive de relatos e sim de significações que são dadas a ela de modo particular e sensível a cada receptor (DEWEY, 2010; SEEL; MORICEAU e PAES, 2014).

Não é por um acaso que a identificação aqui proposta é com uma arte visual, contudo, do mesmo modo a visualidade analisada subentende mais um paradoxo da imagem em uma outra linguagem do que se refere a representação. A natureza expressiva do grafite e sua logística para se concretizar carregam pertinências que fazem parte de ações aventadas por uma percepção e consciência - mesmo que fugazes - capturadas através da experiência do olhar, que está ao alcance da velocidade que se necessita para estar atualizado o máximo possível no tempo mínimo possível.

O por quê da evidência de uma arte de rua marginalizada - ainda hoje de várias maneiras - justamente nos tempos atuais de crises desumanas com o aumento explosivo e trágico de refugiados por boa parte do mundo, e, soma-se a isso, nos tempos de tecnologia e da imagem virtual, são questões que deslocam o próprio grafite de uma margem simplesmente visual e permite-o significar nosso próprio tempo. Como dito, a essência não está no conteúdo capturado pela retina a primeira vista, por isso mesmo uma disposição fenomenológica solicita caminhar por vários grafites ao redor do mundo a fim de estabelecer o conjunto significativo que faz essa arte se presentificar e receber autorizações populares e legais - em alguns casos com suas regras. Desse modo, as imagens - feitas por artistas de rua ou grafiteiros em diversos países - de denúncias do sofrimento de refugiados e mortes em tentativas de travessias por mar, de ataques terroristas e utilização de força armada em manifestações civis, entre outras gritando sobre uma realidade sociopolítica desesperadora, me parecem colocar o grafite em evidência por uma curiosa negação ao virtual. Mas não negação à tecnologia. Quando o que está na margem passa a ser reconhecido pela qualidade artística que se vê com os olhos, com os sentidos - acerca do imaginário (SILVA, 2014a) - e pelos locais onde são produzidos propositalmente, há um deslocamento de classes. O grafite não quer negar, ele permite valorizar o popular respeitando suas condições para obter a experiência. Se não é o objetivo do grafite - uma vez que a significação é dada por nós - essa partilha é seu real efeito (RANCIÉRE, 2009), por isso mesmo marca um momento onde podemos olhar para essa arte e obter identificações culturais e sociais do tempo histórico no qual é exposto.

\section{Como nos olha o que vemos}




\begin{abstract}
Nunca, aparentemente, a imagem - e o arquivo que conforma desde o momento em que se multiplica, por muito pouco que seja, e que se deseja agrupá-la, entender sua multiplicidade - nunca a imagem se impôs com tanta força em nosso universo estético, técnico, cotidiano, político, histórico. Nunca mostrou tantas verdades tão cruas; nunca, sem dúvida, nos mentiu tanto solicitando nossa credulidade; nunca proliferou tanto e nunca sofreu tanta censura e destruição. Nunca, portanto, - esta impressão se deve sem dúvida ao próprio caráter da situação atual, seu caráter ardente -, a imagem sofreu tantos dilaceramentos, tantas reivindicações contraditórias e tantas rejeições cruzadas, manipulações imorais e execrações moralizantes (HUBERMAN, 2012, p. 209).
\end{abstract}

Intencionalmente, este subtítulo se apropria de Didi-Huberman ${ }^{6}$, que por sua vez sugere o que já pronunciava Aby Warburg - "O que se vê, o que nos vê" - em sua experiência cosmogônica (artística e antropológica) com os índios Pueblos, no Novo México entre 1895 e $1896^{7}$, para situar a arte de rua chamada grafite no discurso da imagem neste início de século, discurso esse que, por alguma razão, volta a incomodar e ser conteúdo de discussões em diferentes campos do conhecimento, especialmente notado nas Artes, Filosofia, Psicanálise, Sociologia, Antropologia e História. Qual a razão para esse efeito? Existe uma razão? A preocupação com a razão não se adequa a um pensamento que se pretende justificar por uma dimensão arquetípica - no sentido do inconsciente coletivo de $\mathrm{Jung}^{8}$ - e por uma relação com o Imaginário - no sentido de Gilbert Durand. Para essa conversa, a razão é reveladora de si mesma quando esta não consegue mais se sustentar em confirmações textuais, e a imagem parece responder e manter alguma suficiência isenta de textos ou sons.

Retomar um assunto histórica, ampla e exaustivamente comentado e interpretado, não quer aqui apresentar uma novidade, tão pouco colocar a arte grafite do século XXI como a nova imagem a ser interpretada. Longe desse vício, chegar na arte de rua - ainda reconhecida como grafite, dentre suas variações - não se trata de uma escolha, e sim de uma observação

\footnotetext{
${ }^{6} \mathrm{O}$ autor possui um livro publicado em 1998 sob o título: "O que vemos, O que nos olha", um ensaio sobre problemáticas interpretativas na arte para além das identificações apenas visuais, fornecendo pensamentos sobre o movimento em conjunto que delibera as questões da imagem atualmente; conteúdo e forma; cultura e sociedade; anacronismo e diacronismo - sintoma.

7 Aby Warburg é considerado, segundo literatura da área, o pai de uma moderna Teoria da Imagem. Para cronologia e passagem referida, cf.: MICHAUD, P.-A. Aby Warburg et l'image en mouvement, prefácio de G. DIDI-HUBERMAN e textos de A. WARBURG ("Souvenir d'un Voyage en Pays Pueblo" [1923] e "Projet de Voyage en Amérique" [1927]). Paris: Macula, 1998.

${ }^{8}$ Que é uma forma de conhecimento que parte de tendências e predisposições, e não exclusivamente da experiência sensível. O contexto visual contido no grafite, neste caso, é percebido, não tão longe como estruturas ancestrais - apesar de possibilidades existirem em um estudo específico - mas, é percebido como tendências e predisposições a partir de modos de vida, de comportamentos direcionados pelo desenvolvimento tecnológico e progressos naturais que alteram o todo, inclusive a necessidade de fazer arte.
} 
para fora dela mesma. Do mesmo modo que o sentido da imagem proposto relacional com o grafite não advém deste, não significa, também, tomar as imagens das obras de arte de rua apenas como ícones nem como formas (representações) da sociedade atual, ou seja, aquela imagem vista como intenção cultural, composição artística de rebeldia ou função social, as quais se pode ver na maioria das cidades pelo mundo. A pergunta de aproximação não é se 'vivemos em uma sociedade da imagem'(?), questionamento lídimo já que o destaque no campo das Artes nota-se no crescente desenvolvimento do grafite no mundo. Uma melhor pergunta seria sobre a possível conexão existente entre a realidade de um momento histórico conectado por redes sociais online - onde o se ver é ainda mais importante do que o ver - e a ambientação e práticas que nos exercem essa dinâmica, com a presença de uma arte visual, como a arte de rua e o grafite, onde o ver, mesmo através da janela do ônibus, carro ou caminhando (des)compromissadamente, já subentende uma apreciação tão suficiente e adequada entre o tempo curto e o prático salão/galeria a céu aberto funcionando 24 horas por dia com constantes atualizações, que propõe uma enunciação, um modo coletivo de sentir. Parece dizer sobre nosso padrão de comportamento ao nos olhar.

Outro questionamento surge dentro da realidade do grafite recebendo não somente legalizações sociais, políticas e civis, mas, sobretudo, ganhando espaços culturais de tradição erudita, quando adentra salões de arte, museus, galerias e escolas, interferindo, mais uma vez, na problemática espacial entre popular e erudito - porém, nesse contexto, já se vive, em partes, uma realidade que une essas duas estéticas separadas pelo homem ocidental. O que difere nesse aventar, mais uma vez, é a diferenciação do pensamento - que aqui enfoca essas questões já postas - sob a influência cultural em nós mesmos, cidadãos absorventes não de uma arte, mas de um processo histórico e tecnológico para esse caso, onde a arte se apropria de modo muito maior e mais participativo no cotidiano que nos é imposto.

Após a imagem receber novas perguntas para obter um significado apropriado ao que se observava em obras de arte, Didi-Huberman (2013[orig.:1990]; 2013a[orig.:2002]) se colocou diante delas e deu sentido supremo e autônomo para a imagem. Ranciére (2012) as questionou por vias do destino, comparando-as com outros campos do conhecimento e questionando sua representatividade e suas implicações. Santaella e Nöth (2008) paradigmatizaram as imagens desde a considerada pré-fotográfica, fotográfica e a pósfotográfica, onde se articulam relações com o real e o irreal (o vídeo e o virtual). Filósofos, historiadores da arte e semioticistas, entre outros, não é difícil encontrar pensamentos de campos distintos interessados na imagem e nos seus novos espaços de discussão, necessidade 
e valor. No entanto, a imagem não fala, nós é que falamos por ela e dela e lhe oferecemos definições e sentidos.

Ranciére (2014) nos oferece pistas para esse pensamento quando pergunta como fazer o mudo falar. O que fala não é o objeto em si, mas os movimentos da experiência vivida que constróem a sua existência. O sentido que estamos apresentando ao grafite também pode sofrer a falta de sua própria fala, mas apenas até o momento em que deixamos 'ouví-lo' por outras vias que não os ouvidos ou os olhos: sugiro a via da experiência. Uma comparação seria talvez um exercício inicial. Comparar dinâmicas do grafite com as da vida real. O modo como os interesses acontecem e as relações se manifestam, as redes sociais com diálogos na condição do ideal/irreal, os locais fáceis para se observar ou reconhecer uma obra de arte no muro, na parede, na calçada, a baixo, a cima, onde se estiver, pois é assim que a informação e a comunicação nos chegam na contemporaneidade.

Neste espaço, o grafite é pensado como um documento que nos fornece informações sobre como pensa a sociedade. O modo como essa fonte muda fala, olhando certos modos de agir e de sentir que passam a condicionar os indivíduos em sociedade, descrevem o discurso da imagem que a presença fenomênica dessa arte em territórios continentais (GANZ, 2010) desperta nas sensibilidades do tempo presente, o qual nos referimos como o tempo interpretador. Interpretar não a prática do grafite, mas seu efeito. Todo efeito tem uma causa, e a presença do grafite na sociedade globalizada contemporânea, nas agências e agendas culturais diversas, não se trata de uma coincidência agradável aos olhos, se trata de uma causa real - ainda que exista no sentido fenomenológico - e seus efeitos adentram nosso real simbólico: o imaginário/inconsciente origem de todas as materializações (como defendia Cornelius Castoriadis). Averiguar esses efeitos no cotidiano da vida real e comum, é, não apenas uma proposta de sentido para o espaço do grafite no tempo presente, mas um caminho para observar aspectos socioculturais admitidos pelas estruturas regentes. No momento em que se pode enxergar a partir de percepções vivenciadas em hábitos diários e costumes, as conexões surgem, compreensões ocorrem, uma rede de sentido é conectada à própria experiência de vida.

Retomando o subtítulo, antes de adentrar aos discursos visuais que o grafite revela dentro de uma relação proprioceptiva entre imagem (arte grafite) e contexto social (aspectos tecnológicos e comportamentais), o lugar não é e não pode ser de perguntas. Ora, um objeto mudo não fala. Sua comunicação se encontra em uma dimensão que é sine qua non à própria 
imagem: registros da mente humana e registros por capturas externas, tudo equivale a dimensões do imaginário, que vai além da criação de imagens ou criação por imagens. A imaginação precisa de um imaginário, enquanto o imaginário independe de imagens e suas ações, pois ele as anuncia. O imaginário antecede os sentidos que irã se objetivar. A presença do grafite não possui algum sentido, possui e permite todos os sentidos, uma vez direcionando a reflexão a partir da própria arte, o que sugere ouvir e ver o que esta tem a nos dizer. Quando os efeitos são notados, quando há uma consequência e um movimento de ação, é possível ouvir, enxergar, comentar o mudo, pois ele é uma experiência viva e cotidiana, sensível e afetiva no percurso das "táticas" que operam os "modos de fazer" (CERTEAU, 2014). Quando procuramos não olhar, mas perceber, ou exercitar um olhar com os olhos do Outro (o grafite - imaginar como aquela imagem está me vendo ao existir daquela forma e naquele local), o que recebemos de volta não são simples respostas, são várias consciências conectadas que exercem sentido e lógica entre hábitos comuns, como os efeitos de não mais comprar jornais impressos e ler online notícias reduzidas, diretas e constantemente atualizadas, assim como a constituição da própria arte de rua, que se autentica pela existência em locais fáceis de observar, de rápida absorção e impacto, instantâneo na informação, comunicação ou expressão desejada, pois tem a contemporânea qualidade de ser efêmero e renovado com a velocidade necessária para uma existência sobrevivente.

Se insistimos em pensar no questionamento proposto (subtítulo), 'o que vemos' seria uma proposta de espelho, nudez, incômodo e descoberta, rejeição e/ou aceitação. Quando é observado, o grafite já nos olhou e capturou algo que somente após o reflexo deixado no observador, é possível se pensar em uma reflexão ou sensibilidade, sensação, afetividade exercidas. O grafite está nos olhando e nos contando sobre assuntos e emoções a qualquer hora do dia ou da noite, em qualquer esquina, terreno abandonado, muros de regiões centrais e/ou periféricas, em galerias, salões de arte contemporânea e museus. O que está aparente em seu conteúdo, na imagem que apresenta, ainda não é o que justifica sua existência. Por esse caminho sua voz não ecoa por muito tempo. No entanto, os arquétipos - em uma apropriação 'consciente' de Jung, segundo o qual, imaginário e realidade estão na mesma dimensão para o inconsciente humano - podem nos aproximar da significação da imagem dentro de uma compreensão mais ampla, o imaginário, cujo discurso, está entre os interesses também do sociólogo Michel Maffesoli (2001; 2013), discípulo de Durand, como entre tantos outros pensadores especialmente nas duas primeiras décadas deste início de século. 
Dentro de um contemporâneo lugar para a imagem, o imaginário se faz presente como o real que nos habita em tempos de realidade virtual. Armando Silva diagnosticou um cenário urbano imaginário na sociedade latinoamericana, onde o mecanismo dialógico e comunicacional existentes atualmente, nos coloca em "estranhamentos", e estes levam à uma percepção de vida só possível e explicável dentro do imaginário ${ }^{9}$. Talvez seja prudente lembrar que o imaginário aqui citado, não se trata de invenção ou um mundo fantasioso. Se trata do lugar onde primeiro se estabelece a criação, poéticas de uma possibilidade, uma imagem-ação/imaginação, e então seus gestos são atualizações históricas que estabelecem o funcionamento de formas sociais e culturais. Apesar de importante nessa urdidura, não adentraremos aos conceitos do imaginário, cujo apoio encontramos também, e especialmente, em Gilbert Durand ${ }^{10}$.

Nesse sentido, há uma espécie de convocação ao aspecto visual na sociedade contemporânea (após Sociedade do Espetáculo de Guy Debord, e Simulacros e Simulação, de Jean Baudrillard). Apenas considerando dois marcadores: o uso do corpo nas artes da Performance ${ }^{11}$, e o uso do corpo na arte sonora - a Música - com a insurgência de grupos ou cantores solos demarcando sua imagem corporal de acordo com sua identidade de gênero ${ }^{12}$, surge um deslocamento tendencioso ao que está disponível aos olhos. Com esse enfoque, provocamos a lembrança da qual sugere ainda mais argumentos dentro do contexto da imagem, que é o fato do movimento de grafitar ter surgido, também - não exclusivamente - a partir da música que se fazia dentro de uma atitude racial, o Rap dentro do movimento Hip$H o p^{13}$. O século XX recebeu créditos pela música, foi considerado o século da canção.

\footnotetext{
${ }^{9}$ A respeito de um extenso trabalho de pesquisa na América Latina, Armando Silva lançou dois livros que destaco aqui como referência para um aspecto do imaginário urbano relacionado à arte de rua: "Imaginários Estranhamentos Urbanos”, 2014; e, “Atmosferas Urbanas: Grafite, Arte Pública, Nichos Estéticos”, 2014.

${ }^{10}$ Sobre o Imaginário ver: "As estruturas antropológicas do imaginário". $3^{\circ}$ e $4^{\circ}$ edições pela editora Martins Fontes, respectivamente, 2002 e 2012.

${ }^{11}$ Como exemplo, em RoseLee Goldberg. "A arte da Performance - do Futurismo ao Presente". São Paulo: Martins Fontes, 2006

${ }^{12}$ No cenário da música popular de massa da indústria brasileira nas duas últimas décadas, se destacam artistas e grupos musicais visualmente preocupados com questões de gênero, dentre alguns nomes: Liniker, Rico Dalasam, Pabllo Vittar, As Bahias e a Cozinha Mineira, Jaloo, Linn da Quebrada, Johnny Hooker, Rosa Luz, ... https://mdemulher.abril.com.br/cultura/11-artistas-brasileiros-que-estao-quebrando-todas-as-regras-de-genero/ https://www.vice.com/pt br/article/9kg7gv/cinco-artistas-brasileiros-lgbtq-falam-sobre-identidade-censura-e$\underline{\text { sobrevivencia }}$
}

${ }^{13}$ Segundo Roberto Camargos, em: "Rap e Política: Percepções da vida social brasileira", 2015, o Rap surge nos Estados Unidos, no Bronx, já em fins da década de 1960. No Brasil, aparece em meados da década de 1980. Não é difícil verificar a valorização da política, da imagem visual nas roupas, acessórios, faces dominantes e 
Interessante notar que justamente a música se reinventa pelo aspecto da visualidade, e o grafite - por excelência - adentra o próximo século creditando de imagens e visibilidades o tempo presente com a mesma intensidade, ou ainda mais, com a qual a batida e o fenômeno Pop contagiou a "modernidade ocidental" (GILROY, 2001).

Mas o grafite ocupa um lugar diferente desses mundos paradigmáticos, representacionais e autônomos da imagem. Ele não se encaixa nem mesmo no pós-fotográfico (retomando Santaella e Nöth) irreal - apesar de ser uma arte que dinamize espaço/tempo com sua flexibilidade de locais e certa valorização pela impermanência de suas obras - por uma característica que testemunha sua estética e uma devida valorização a um, talvez, novo conceito de popular: a presença.

De forma direta e abrangente, a palavra presença implica na ação de ver, testemunhar ou ainda sentir. É recebida neste raciocínio como imperativo também do popular, que nesse caso se refere ao acesso livre e aberto no qual o grafite se registra e, consequentemente, resulta na experiência estética quando a presença se revela, metodologicamente, na qualidade sensível da vida comum, cotidiana, tornando estético a própria existência (DEWEY, 2010; SHUSTERMAN, 1998; SEEL, 2014). Portanto, a presença se insere em condições dialógicas, simbólicas, representativas e significativas na relação que entendemos contemporânea entre arte e cultura, que é a relação: grafite, territórios de classe popular/erudito e experiência estética.

Ao considerar que o grafite não se encaixa no paradigma pós-fotográfico, dentro do referido trabalho de Santaella e Nöth, 2008, apenas conduzimos o paradigma da imagem que o grafite propõe nessa discussão, a uma compreensão oposta ao irreal que o conteúdo da imagem virtual - o pós-fotográfico - pode suscitar. Uma das razões para o interesse que vem destacando o contexto da imagem em diversos campos de conhecimento nas primeiras décadas deste século, parte do modo de pensar como a relação entre pessoas, seja profissionalmente ou pessoalmente é alimentada por domínios inerentes a redes online de comunicação. A imagem da própria pessoa (foto) utilizada como conteúdo para uma conversa, ou a imagem icônica (emoticons = emoção+ícone) com a qual se

principalmente a fala ritmada, em detrimento da melodia e de uma construção musical complexa e elaborada. Sobre isso, cf.: Maria Regiane Barrozo, "Ethnical Beat: Expressão Sintomática da Música", 2019, EdUFMT. A respeito da música negra diaspórica como principal expressão cultural globalizada no século XX, ver: Paul Gilroy, “O Atlântico Negro: Modernidade e dupla Consciência”, 2001, Ed. 34. 
comunica/conversa, mostram apenas a superfície de um mundo cujo funcionamento depende de cognições que os olhos podem canalizar mais rapidamente. $\mathrm{O}$ apelo visual vai muito além desse contexto, constrói todo um padrão que influencia os modos de agir e ser na vida. Costumes, práticas não fogem mais ao apelo visual e convencionam a sociedade contemporânea à uma aproximação com o universo mental criado pelo imperativo da imagem, com a mentalidade anunciada por produções em contexto virtual.

E assim, a arte de rua chamada grafite parece assegurar uma parte real, neste universo de práticas e intenções imagéticas irreais até mesmo para os olhos que as enxergam - são irreais também na veracidade da existência, pois falseiam, mentem e enganam quem se vale delas de alguma forma. Essa parte real sugere o discurso da imagem proposto, ao reconhecer práticas do 'ao vivo', sendo transmitidos qualquer movimento de uma pessoa em tempo real pelas redes sociais - live. O real na arte grafite e sociedade contemporâneas - ao contrário de vinculações imaginativas no sentido de invenções dadas às artes especialmente no século XIX e em movimentos artísticos como o surrealismo no século XX - discursam uma referência à imagem instantânea, a qual se pode comprovar em poucos minutos e principalmente, se pode opinar e registrar sua parte como reflexo no espelho, para ser visto por outros.

O cinema também foi alvo do que aqui consideramos um impulso ao real. No livro "Filmar o Real: Sobre o Documentário Brasileiro Contemporâneo", Consuelo Lins e Cláudia Regina observam o crescente interesse pelo modelo documentário de fazer filme, com capturas de imagens de cenas reais, sem tratamentos de câmera, mostrando como de fato é o mundo real dentro de uma produção que também contempla irrealidades. As autoras questionam o motivo da grande atração que o formato documental tem exercido a partir da última década do XX até os recentes trabalhos para além do território nacional.

Os sinais da força do documentário são até mais consistentes em países da Europa na França, particularmente -, nos Estados Unidos, Canadá, Japão, Israel, entre outros. É importante notar ainda que o interesse por imagens "reais" tampouco se limita ao campo do documentário: parece corresponder a uma atração cada vez maior pelo "real" em diversas formas de expressão artísticas e midiáticas. Parte significativa das ficções cinematográficas e mesmo televisivas tem investido em uma estética de teor documental, e são expressivas as adaptações de relatos literários cuja matéria são situações reais. Os telejornais e programas de variedades não se limitam mais às imagens estáveis e bem enquadradas, utilizando em muitas coberturas planos-sequências tremidos e imagens de baixa qualidade registradas por micro-câmeras, câmeras de vigilância, amadoras e de telefones celulares, buscando imprimir - ainda que de maneira limitada e "domesticada" - um "efeito de realidade" à assepsia estética que imperava no telejornalismo até o início dos anos 90 (REGINA e LINS, 2008, 1. 39, 45). 
O discurso da imagem pensado a partir do grafite como fenômeno sintomático parece paradigmatizar conceitos e definições a respeito da imagem ao longo de sua história. Atributos mnemônicos, estéticos e indutivos, já não sugerem tão intensamente a constituição e o objeto da imagem, neste cenário sugerido. O caráter real chama a atenção e talvez não seja fortuito no momento em que ouvidos e olhos se acostumam com as chamadas "fake news". Imprudente seria desconsiderar a arte - o subjetivo - quando se pretende compreender o real, esteja ele para a dimensão da realidade ou do imaginário. E, concordando com a psicanálise Junguiana e as definições sobre o imaginário para a filosofia desde Gilbert Durand e Warburg e através de autores como Hans Belting, Armando Silva, Didi-Huberman, Rancière, entre outros, o imaginário é o que constrói a realidade. O mundo real que a imagem tanto quer ver e se expressa nas artes e se concretiza nos movimentos cotidianos e nas experiências da vida comum - nada mais é que consequências de nós mesmos. Mostra uma dupla consciência, o jogo existencial entre o real e o imaginário mais imantados em urdiduras humanas do que nunca. Revela status em redes sociais: 'enxergue-me ou te devoro'. Ou, “quando as imagens tocam o real" e pergunta a este: "Não vês que ardo?" (HUBERMAN, 2012, p. 216). Pois, para Didi-Huberman, para ver o real é preciso se aproximar da imagem que o apresenta, e esta queima em contato com o real, se torna cinzas. É preciso "soprar suavemente para que a brasa, sob as cinzas, volte a emitir seu calor, seu resplendor, seu perigo" (ibid.).

A referência feita rapidamente a uma diáspora dos refugiados, realidade desse exato momento, é também marcada pela presença, mas uma presença trans, multi e intercultural de experiências confrontadas, trocadas e, com o passar do tempo, reinventadas. Essa observação, ainda a nível do devir, apenas pretende ocorrer como identificações com a presença, citadas, uma vez que, a arte por meio da imagem e da permeabilidade - entre tantas características móveis e dinâmicas do grafite - me parece ter a melhor capacidade para atender as representações e subjetivações de tantas culturas em cruzamentos. O grafite facilita reterritorializações através da particularidade de colocar as culturas no movimento e no espaço em que elas transitam e sofrem suas reinvenções, e, utiliza para isso apenas um elemento: a própria experiência de vida, que é a estética do grafite enquanto cultura contemporânea, a qual compreende: imagens em movimento e vidas em movimento - grafite e refugiados/migrantes, ambos em processo crescente e atual de reterritorializações.

\subsection{Discursos visuais}


O grafite sedia uma inflexão para pensarmos de que maneira somos vistos pela arte. Se a imagem tivesse voz, o que ouviríamos sobre nossos próprios comportamentos sociais? Nesse caso, o que há, ou, que tipo de saber infiltra-se com os espaços da vida comum atual, entrecruzando os sentidos estéticos e/ou de classe? Por uma perspectiva, o axioma está dado, e dessa vez por um veículo popular, basta agora saber olhar de volta para esse espelho. Convocamos um retorno do olhar à guisa de observações de sinais, sintomas, percepções de sensibilidades vivenciadas.

Conduzir um objeto artístico como fonte reveladora de aspectos sintomáticos como indícios para se refletir cultural e socialmente o momento histórico presente, trouxe o grafite como paradigma indiciário no contexto da imagem. Algumas dessas fontes indiciárias são pensadas de acordo com algumas relações de sentido a partir de experiências da vida comum no cotidiano contemporâneo:

- O EFÊMERO: desde o início da sua história mais recente - no século XX - a prática do grafite é uma expressão informativa, uma “intervenção na cidade, não mais como lugar do poder econômico e político, mas sim como espaço/tempo do poder terrorista dos mídia, dos signos e da cultura dominante" (BAUDRILLARD, 1979, p. 315. Grifo nosso). A arte de rua concorre como uma grande mídia, mesmo a arte considerada grafite ou pichação. O que é anunciado, revelado, denunciado, ou qualquer outro motivo que o valha, perde o sentido na permanência, tanto pelo fato da necessidade de expor outros dados ou assuntos, quanto pelo exercício de refazer, que parece ser a dinâmica por excelência dessa arte. Essa mesma efemeridade parece ocorrer também, com certa primazia outra, no modo como recebemos e absorvemos boa parte das informações e notícias em aparelhos móveis ao longo de um dia. Não é possível acumular diante da quantidade, por isso, o efêmero se torna uma qualidade comum na relação com informações e comunicações. 


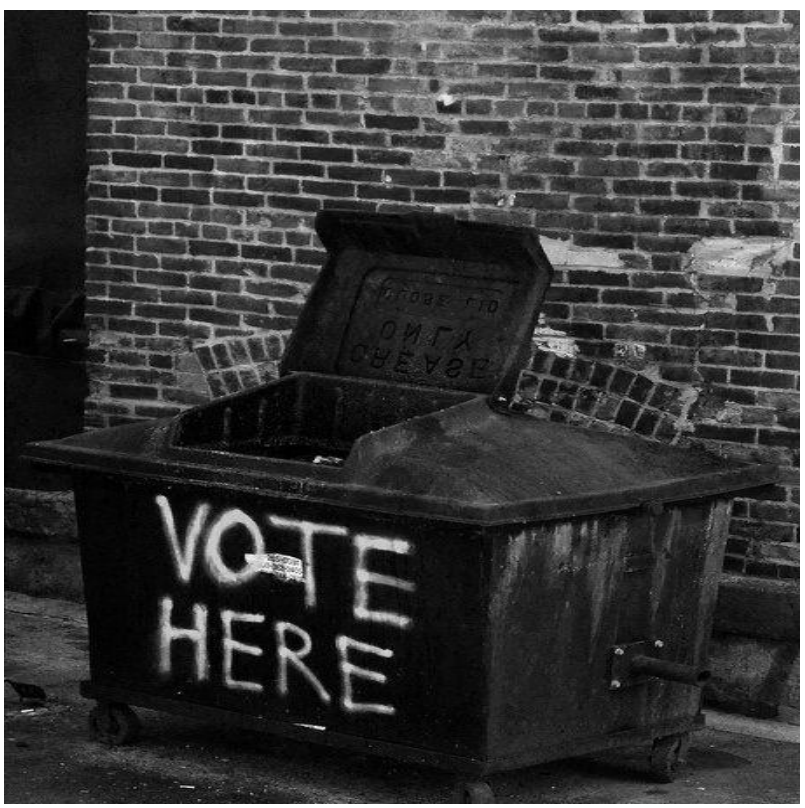

Figura 1 - Anônimo.

Fonte:

https://br.pinterest.com/pin/477100154244679173/?nic_v1=1aWXGK8Rm81t5k0jQZL5pW8kyYKD\%2Fn6Z3KOMJsEmg OJcTTip8ZsaV\%2FfhRHD4pzYb72

- O ATUALIZADO/NOVO: a internet apresentou ao mundo agilidades, não necessariamente em conhecimento, de um modo geral, mas em informações e facilidades. Realidade esta que alimenta uma postura de constante atualização. O novo fica velho muito rapidamente, uma vez que qualquer acontecimento ganha logo os veículos sociais na rede online ilimitada. O que foi 'visto' - diferente de lido e compreendido - hoje, se novamente cruza os olhos, um estranho desconforto sugere à mente algo como 'atrasado'. O grafite se manifesta por meio da atualização e da novidade. Sim, o motivo de suas imagens e conteúdo sugerem essa necessidade, de apresentar o sentido daquilo que acontece atualmente. Há também o suporte, que na arte de rua não se define, por ser possível se manifestar em qualquer ou nenhum suporte físico dado ou construído na cidade. No grafite, o suporte faz parte da própria arte, complementa seu sentido, seu objetivo, por isso, pode ser feito em qualquer superfície, natureza ou objeto, inclusive naquele que será descartado em pouco tempo. Assim como a notícia, o grafite amanhã será outro pelo fato dele pulsar no andamento da cidade, no ritmo do movimento físico que ela impõe aos seus. Esse caráter de novidade, atualização e adaptação, faz da arte de rua, ou ainda, da arte da imagem, cúmplice de seu próprio tempo. 


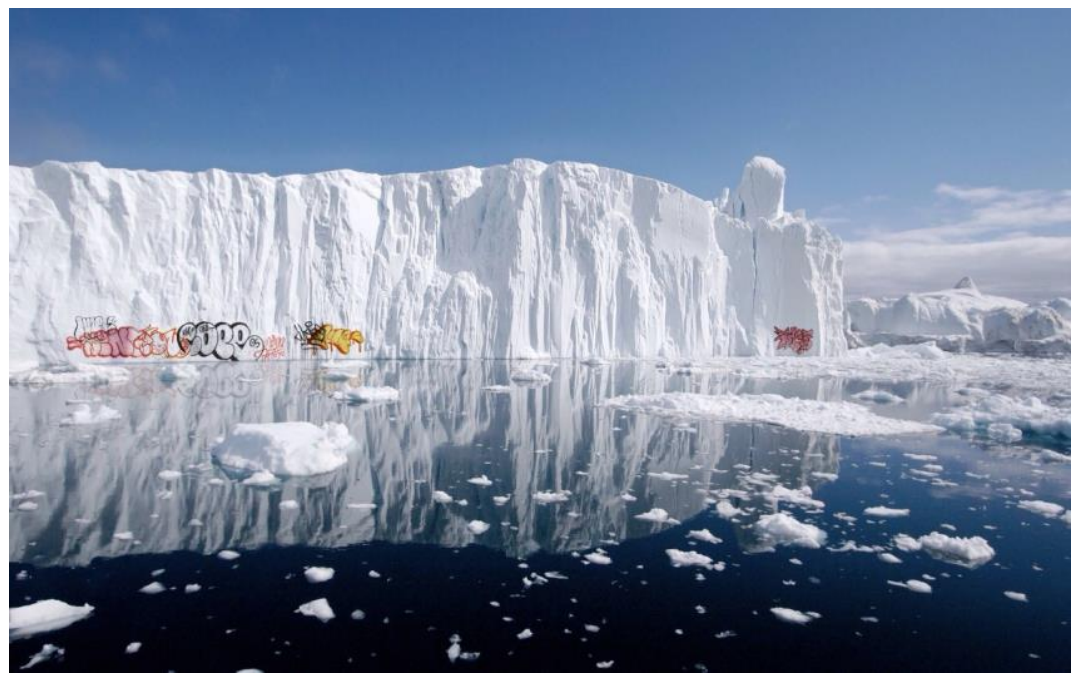

Figura 2 - Costa da Antártida.

Fonte: https://wallhere.com/pt/wallpaper/1261967

- O BREVE/CURTO: brevidade é como o ar que se respira. Os 'três minutos' estão para os vídeos no youtube do mesmo modo como as curtas mensagens estão para o whatsapp e as pequenas e sucintas reportagens estão para os jornais online - não ultrapasse sob risco de ser ignorado! De modo particular ao youtube, a fragmentação daquilo que se pretende expor - devido ao cansaço de um expectador (seguidor) que não tem somente aquele canal para 'comprovar sua busca' e/ou dar likes - é um importante sintoma de um esgotamento informacional, ao lado, é claro, de uma pretensa infinitude de versões, canais, endereços online internacionais, possibilitando uma aquisição de dados ou conhecimento, a princípio, de alta qualidade. Ocorre na manifestação do grafite semelhante atitude, ao que se nota tanto pelo espaço, que muitas vezes se resume a um buraco na calçada, um detalhe em uma grade, quanto pelo exercício da realização, o qual pode não contemplar um local seguro, uma imagem ou provocação adequada à ordem e à moral públicas, exigindo à prática desta arte, uma ação sinóptica. O registro desta em diversos locais, sem uma delimitação que a impeça, também é observado como dinâmica de aproximação entre arte e experiência na prática, no cotidiano da vida real e atual. 


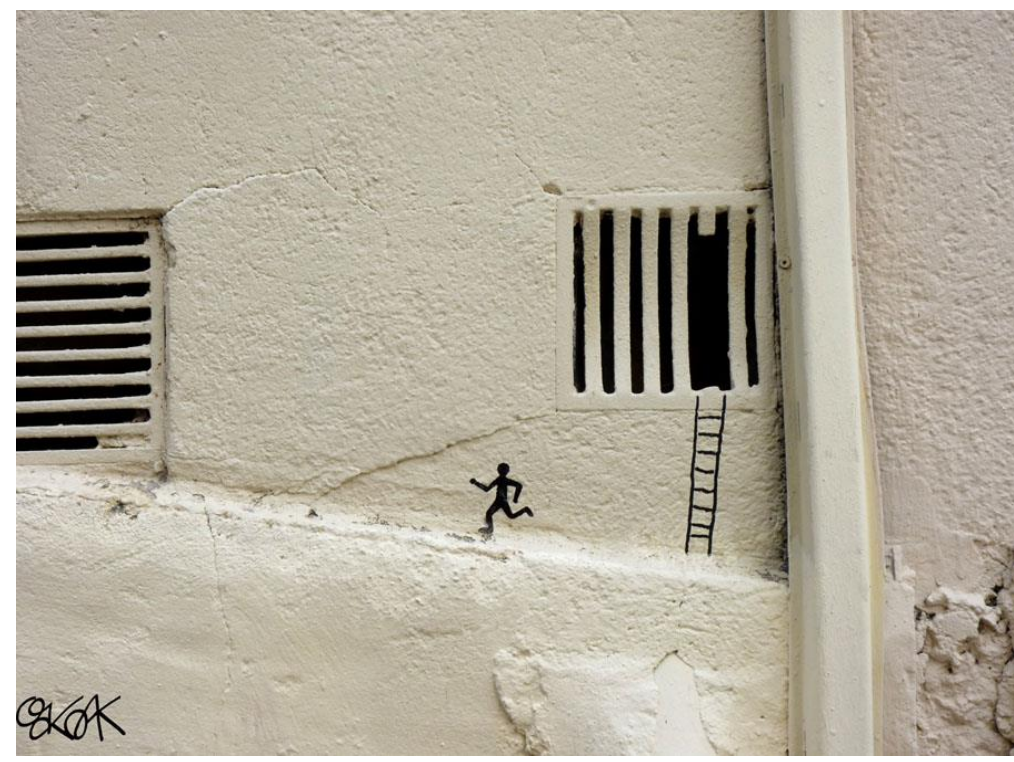

Figura 3 - "A FUGA", OaKoaK - Lyon, França 2012.

Fonte: https://www.hypeness.com.br/2013/01/conheca-mais-intervencoes-engracadas-e-criativas-de-oakoak/

- O FALSO-VERDADEIRO: o grafite convive em harmonia nesse contexto facilitador para invenções e divulgações falsas na mesma medida da sua existência e sua prática. Essa medida é a da reinvenção. Na história da música negra norte-americana, a mesma música (ritmo, batida reinventados) atualmente globalizada, os artistas negros precisaram suportar algumas adaptações e negociações que envolviam negações identitárias de várias formas ${ }^{14}$. Esse histórico musical que desencadeou no Rap e consequentemente no grafite, está sugerido aqui pelo fato da reinvenção ser um atributo inegável ao percurso de sobrevivência diaspórica nas Américas, artisticamente falando, e o grafite carregar em seu acontecimento, a facilidade de revelar e velar conteúdo e forma de acordo com o 'suporte' que tens a frente - os espaços da cidade e seus objetos. Em outras palavras, o cenário para o grafite é uma dinâmica de experiência, onde o suporte não precisa ser justificado por uma estética ou regimento performático moderno ou pós-moderno. O que menos importa é se o conteúdo que a imagem percebida com os olhos - e não sentida a partir do olhar - remete à uma informação ou comunicação verdadeira ou falsa, isso fica para o imaginário tratado pela psicanálise. O discurso visual que traz o sentido de verdade ou falsidade nesta

\footnotetext{
14 A música negra norte-americana no século XX constitui uma expressão de onde se revela política e socialmente mecanismos de defesa, ataques, adaptações e sobrevivência de toda uma população de origem diaspórica, e, também, uma expressão de constantes reinvenções sonoras e performáticas, o que levou ao ritmo e ao fenômeno Pop. Sobre isso, ver: Eric J. Hobsbawm, "História Social do Jazz", 1990; Joachim E. Berendt, "O Jazz do Rag ao Rock, 2007”; Carlos Calado, “O Jazz como Espetáculo”, 1990.
} 
arte contemporânea, corresponde ao exercício de fazer, as "táticas" de sobrevivência (CERTEAU, 2014), agenciadas pelas performatividades necessárias à sua expressão, destacando neste aspecto de interesse, os locais onde são praticadas as várias vertentes do grafite, os quais transitam hoje entre o popular e o erudito (galerias de arte e muros periféricos e centralizados), levantando diálogos sobre o que é o grafite hoje, originalidade e fusões éticas e étnicas.

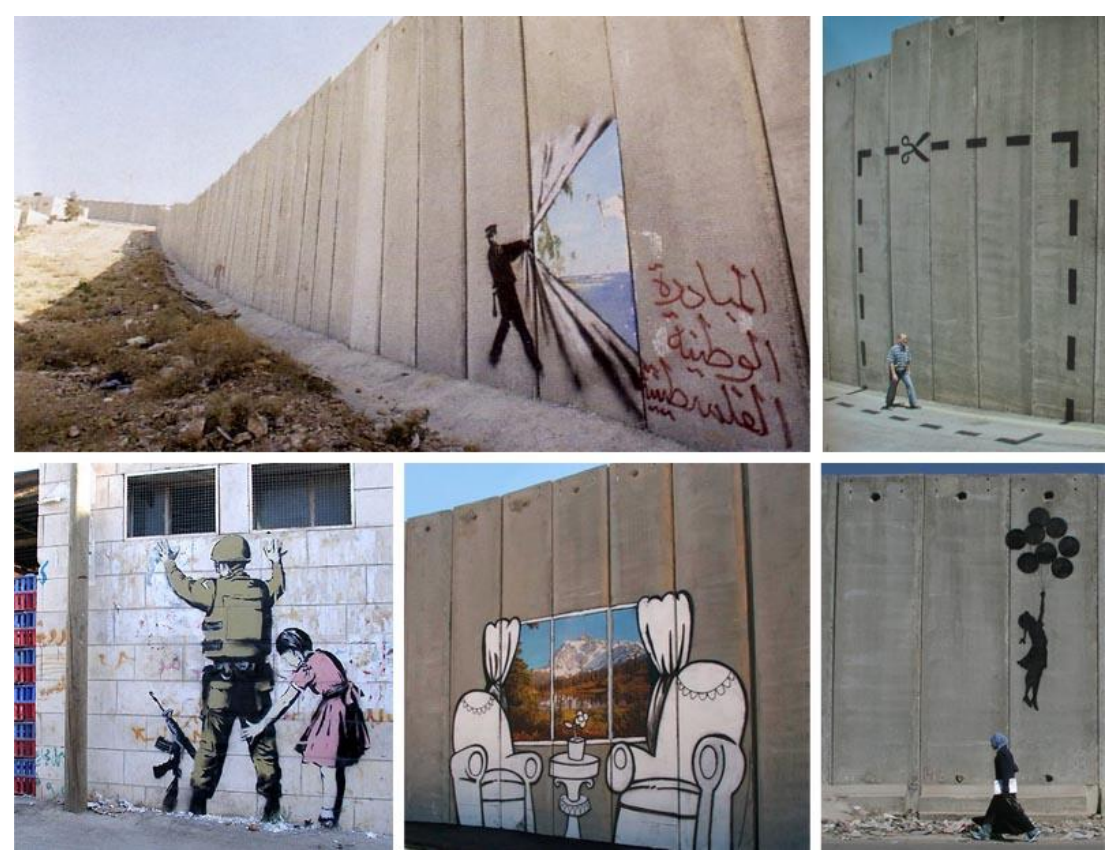

Figura 4 - Muro da Cisjordânia, Banksy. Fonte: https://360photography.in/?p=19869

Um discurso que nega posicionamentos classificatórios, estilísticos e estéticos. O grafite não é um convidado nesta festa, ele é a natural ocorrência percebida na contemporaneidade, provocador do protagonismo implícito entre arte e cultura atuais. Para tanto, sua investida se faz em natureza fenomenológica. "Phainomenon (fenômeno) significa aquilo que se mostra por si mesmo, o manifesto. Logos é tomado aqui com o significado de discurso esclarecedor. Desta maneira, 'fenomenologia' significa discurso esclarecedor a respeito daquilo que se mostra por si mesmo" (MARTINS; DICHTCHEKENIAN, 1984, p. 70). Portanto, sendo o fenômeno "aquilo que se manifesta em si mesmo" (ibid. p. 79), e o grafite observado neste pensamento como fenômeno, fica claro a limitação temporal recente e ainda em curso observada para este texto, notificada a respeito uma realidade um pouco diferente que o grafite experiencia em casos de atuação profissional. Se trata de sua mercadologização, sua realização por encomendas. Fato que desloca alguns discursos sociais (naturalmente modificados e reinventados ao longo do tempo - tempo este cada vez menos 
longo...) como as dinâmicas efêmeras, velozes e políticas que definiram-no, podendo evidenciar uma mudança no fenômeno que atualmente se encarrega de historicizar a arte visual e arte de rua contemporâneas - e por isso mesmo, esclarece ao se manifestar.

Ainda assim, o manifesto grafite continua autônomo, espontâneo, efêmero, como atributo de origem, e revelador como capacidade de experiência. Por esse motivo, evidencia imaginários e realidades, padrões e modelos de práticas e costumes socioculturais implícitos nas performances de suas presenças.

Reitero que os aspectos do grafite tratados para esta reflexão, não são definidores do conceito de grafite, o qual se manifesta com muitas outras denominações (SILVA, 2014)), como também não são determinantes com relação ao seu exercício, sua função e política. Isso diante das inúmeras formas de práticas que essa arte conquistou e vem usufruindo. O caráter fugitivo e delinquente já não define em uma totalidade a sua dinâmica. Ter um grafite em uma propriedade particular é obter uma obra de arte, em alguns casos. Essa presença não se pode negar, assim como o contrário ainda é real e corriqueiro. Portanto, é um momento de trânsitos, alterações e reinvenções, e, comum a estes momentos, há uma ebulição contagiante.

"Ver nas imagens o lugar de onde se sofre, o lugar de onde se expressam os sintomas" (HUBERMAN, 2012, p. 214). Lembrando Aby Warburg, Didi-Huberman faz essa afirmativa supondo “olhar 'a arte' a partir de sua função vital: urgente, ardente, tanto como paciente [...] e não quem é culpável [...]" (ibid.). Os quatro discursos acima sugeridos (O efêmero; O novo/atualizado; O breve/curto; O falso-verdadeiro) partem do lugar da experiência, da prática, de onde sofre. A própria rotina de vida traz aquelas relações tão iniciais ainda, e já tão dominantes. Ser efêmero, atualizado, breve, verdadeiro e falso, parecem elementos naturais na atuação do "mundo da vida", utilizando palavras de Schutz. Interessante é encaixar esses elementos na produção da arte de rua chamada grafite, o lugar de onde se expressam os sintomas, onde as imagens mostram o lugar onde se queima quando encontra o real. Esses sintomas dialogam de tal forma - entre arte e contemporaneidade - que arte e vida, imaginação e realidade parecem se associar, diluir representações e fazer parte de um lugar onde cabem todos os/em trânsitos. Esse lugar talvez seja o imaginário, tão contemporaneamente real.

De um modo geral, as observações têm conduzido a um discurso onde constitutivos peculiares da ação visual, dos movimentos gerados pelo olhar, são peculiares conducentes de nossa atual e real sociedade. Não obstante, é nesse mesmo momento em que o grafite se revela como nunca antes. Porque a imagem não é mais representação, não é mais um objeto. 
Imagem é o sentido que move a sensibilidade presente de estar no mundo. Por trás da arte de rua que agencia o grafite e este o contexto da imagem, operam complexos mentais e emocionais amplos e inegáveis.

\section{Referências}

BAUDRILlARD, J. Koll Killer ou a Insurreição pelos Signos. Cine Olho - Revista do Centro de Artes Cinematográficas, no 5/6, p. 315-324, jun/jul/ago. 1979. Trad. Fernando Mesquita. Disponível em: https://pt.scribd.com/document/342369066/KOOL-KILLER-OUA-INSSURREICAO-PELOS-SIGNOS-pdf. Acesso em: 13 de março de 2020.

CAMARGOS, R. Rap e política: percepções da vida social brasileira. São Paulo: Boitempo, 2015. 191 p. (Obra completa)

CERTEAU, M. A invenção do cotidiano: 1. Artes de fazer. Trad. Ephraim Ferreira Alves. Petrópolis: Vozes, 2014. 319 p. (Obra completa)

DEWEY, J. A arte como experiência. Trad. Vera Ribeiro. São Paulo: Martins Fontes, 2010. 648 p. (Obra completa)

DICHTCHEKENIAN, M. F. S.; MARTINS, J. (Org). Temas fundamentais de Fenomenologia. Centro de estudos Fenomenológicos de São Paulo. São Paulo: Ed. Moraes, 1984. 98 p. (Obra completa)

DIDI-HUBERMAN, G. A imagem sobrevivente: história da arte e tempo dos fantasmas segundo Aby Warburg. Trad. Vera Ribeiro. Rio de Janeiro: Contraponto, 2013a. 508 p. (Obra completa)

Diante da Imagem. Trad. Paulo Neves. São Paulo: Editora 34, 2013. 360 p. (Obra completa)

. Imagens apesar de tudo. Trad. Vanessa Brito e João Pedro Cachopo. Lisboa: IMAGO, 2012a. 251 p. (Obra completa)

- Quando as imagens tocam o real. Trad. Patrícia Carmello e Vera Nova. Pós: Revista do Programa de Pós Graduação em Artes da Escola de Belas Artes da UFMG, Belo Horizonte, v. 2, n.4, p. 204-219, nov. 2012. ISSN ELETRÔNICO 2238-2046. Disponível em: https://periodicos.ufmg.br/index.php/revistapos/article/view/15454. Acesso em: 13 março 2020. (Artigo em Periódico Digital)

GANZ, N. $O$ mundo do grafite: arte urbana dos cinco continentes. Trad. Rogério Bettoni. São Paulo: Martins Fontes, 2010. 391 p. (Obra completa) 
GILROY, P. O Atlântico negro: modernidade e dupla consciência. Trad. Cid Knipel Moreira. Rio de Janeiro: Ed. 34, 2001. 432 p. (Obra completa)

JUNG, C. G. (1934). Arquétipos e o inconsciente coletivo. Trad. Maria Luiza Appy; Dora mariana R. Ferreira da Silva. Petrópolis: Vozes, 2000. (2 $2^{\circ}$ Edição das Obras Completas de C.G. Jung, v. IX/I) (Obra completa)

LINS, C.; MESQUITA, C. Filmar o real: sobre o documentário brasileiro contemporâneo. Rio de Janeiro: Zahar, 2008. ebook: Amazon. (Obra completa/Livro virtual)

MAFFESOLI, M. O imaginário é uma realidade. FAMECOS: mídia, cultura e tecnologia Revista da Escola de Comunicação, Artes e Design, n 15, agosto, 2001. Porto Alegre. ISSN: 1415-0549 (impresso) 1980-3729 (online). Disponível em: http://revistaseletronicas.pucrs.br/ojs/index.php/revistafamecos/article/view/3123/2395

Acesso em: 10 março 2020. (Artigo em Periódico Digital)

Michel Maffesoli: a pós-modernidade se orienta para "algo de anarquista”. Em Questão - Revista da Faculdade de Biblioteconomia e Comunicação, v. 19, $\mathrm{n}^{\mathrm{o}}$ 2, jul/dez, 2013. E-ISSN: 1808-5245. Disponível em: http://revistaseletronicas.pucrs.br/ojs/index.php/revistafamecos/article/view/3123. Acesso em: 10 março 2020. (Artigo em Periódico Digital)

NÖTH, W.; SANTAELLA, L. Imagem: cognição, semiótica, mídia. São Paulo: Iluminuras, 2008. 240 p. (Obra completa)

PAES, I.; MORICEAU, J. Performances acadêmicas e experiência estética: um lugar ao sensível na construção do sentido. In: PICADO, B.; MENDONÇA, C. C.; FILHO, J. C. (Org). Experiência Estética e Performance. Salvador-BA: EDUFBA, 2014. p. 107-129. (Capítulo de Livro)

RANCIÉRE, J. A partilha do sensível: estética e política. Trad. Mônica Costa Neto. São Paulo: EXO experimental org.: Editora 34, 2009. 72 p. (Obra completa)

O destino das imagens. Trad. Mônica Costa Neto. Rio de Janeiro: Contraponto, 2012. 152 p. (Obra completa)

Os nomes da história: ensaio de poética do saber. Trad. Mariana Echalar. São Paulo: Unesp, 2014. 161 p. (Obra completa)

SCHUSTERMAN, R. Vivendo a arte: o pensamento pragmatista e a estética popular. Trad. Gisela Domschke. São Paulo: Ed.34, 1998. 272 p. (Obra completa) 
SEEL, M. No escopo da experiência estética. In: PICADO, B.; MENDONÇA, C. C.; FILHO, J. C. (Org). Experiência Estética e Performance. Salvador-BA: EDUFBA, 2014. p. 23-36. (Capítulo de Livro)

SILVA, A. Atmosferas Urbanas: grafite, arte pública, nichos estéticos. Trad. Sandra Trabucco Valenzuela. São Paulo: Edições Sesc São Paulo, 2014. 240 p. (Obra completa)

Imaginários: estranhamentos urbanos. Trad. Carmen Ferrer. São Paulo: Edições Sesc São Paulo, 2014a. 248 p. (Obra completa) 